\title{
Effect of Process Variables on the Chemical Constituents and Sensory Characteristics of Nigerian Green Tea
}

Odunmbaku LA ${ }^{1 *}$, Babajide $\mathrm{JM}^{2}$, Shittu $\mathrm{TA}^{2}$, Aroyeun $\mathrm{SO}^{3}$ and Eromosele $\mathrm{CO}^{4}$

${ }^{1}$ Food Technology Department, Moshood Abiola Polytechnic, Abeokuta, Nigeria

${ }^{2}$ Food Science and Technology Department, Federal University of Agriculture, Abeokuta, Nigeria

${ }^{3}$ Cocoa Research Institute of Nigeria, Ibadan, Nigeria

${ }^{4}$ Chemistry Department, Federal University of Agriculture, Abeokuta, Nigeria

\begin{abstract}
Green tea possesses functional properties with attendant health benefits, Nigerian tea leaves has only been commercially processed into black tea. This study therefore evaluated the effect of Steaming Time (ST), Drying Temperature (DT) and Drying time (Dt) on the chemical and sensory properties of Nigerian Green Tea (NGT). Epical bud and two leaves from agronomic proven commercially viable clone were harvested from the Cocoa Research Institute of Nigeria experimental tea plots, Taraba State. Response surface methodology (Central Composite Design) was used to combine the three processing variables: ST (60, 90 and $120 \mathrm{~s}), \mathrm{DT}\left(60,65\right.$ and $\left.70^{\circ} \mathrm{C}\right)$ and $\mathrm{Dt}(90,120$ and $150 \mathrm{~min})$. Epigallocatechin gallate (EGCG), Epigallocatechin (EGC), Epicatechin gallate (ECG) and Epicatechin (EC) contents of NGT were determined using High Performance Liquid Chromatography while descriptive sensory evaluation of NGT samples was carried out using semi trained panellist. Data generated were subjected to ANOVA and regression analysis. Results showed that NGT contain EGCG, EGC, EC and ECG contents that ranged from 46.90 to $178,0.30$ to $4.24,1.03$ to 8.83 , and 8.05 to $33.96(\mathrm{mg} / \mathrm{g})$, respectively. Greenness, sweetness, bitterness, and astringency score of NGT extracts were 4.00-6.00,1.00-2.23, 5.07-7.97 and 1.00-2.23 respectively on a 1-9 intensity scale. This study revealed that acceptable green tea can be obtained from Nigerian tea leaves in terms of chemical constituents, especially for the high EGCG content. The optimum process conditions for NGT were steaming for $60 \mathrm{~s}$ and drying at $70^{\circ} \mathrm{C}$ for 150 min for high EGCG content and sensory acceptability.
\end{abstract}

Keywords: Camellia; Catechin; Optimization; Polyphenol; Tea

\section{Introduction}

Teas are classified into three major types depending on the manufacturing process: 'non-fermented' green tea; 'semi-fermented' oolong tea and 'fermented' black tea [1,2]. Green tea has long been exclusively consumed by the Chinese and Japanese, with cultural ties dating to the first millennium A.D. and, in particular, to tea ceremonies from the twelfth century. Gradually, green tea has received global acceptance due in part to the special health characteristics that have become more widely known through extensive scientific study.

Green tea has been considered a medicine and a healthful beverage since the olden days. The traditional Chinese medicine do recommend tea plant for headaches, body aches and pains, digestion, depression, detoxification, as an energizer and in general, longevity of life.

Several studies have established that, within each category of tea, differences in characteristics exist due to factors such as differences in the processing methods, stage of maturity of tea leaves at harvest, type of tree species, and the region where the tea was cultivated [3-5].

Tea importation to Nigeria has continued to increase steadily since the year 2003. The growth according to the Food and Agricultural Organisation was not unconnected with the perceived health benefit of tea consumption and as such, there is a need to develop the indigenous tea industry. It is equally important to translate the agronomical efforts on tea to more viable and economical ends. The objective of this study therefore is to determine the effect of steaming time, drying temperature and drying time on the chemical and sensory qualities of Nigerian Green tea.

\section{Materials and Methods}

\section{Tea shoots sampling}

Tea shoots comprising of apical bud and two leaves from agronomic proven commercially viable tea clone were harvest from the Cocoa Research Institute of Nigeria experimental tea plots, Taraba State, Nigeria. The plucked shoots were steamed, rolled and oven dried to make green tea.

\section{Product optimization}

Surface response methodology using Central Composite Design (CCD) at three levels, three variables was adopted in optimizing the process variables to obtain 15 experimental runs. The three independent variables experimented were; the steaming time, $(60$, 90 and $120 \mathrm{~s})$, drying temperature $\left(60,65\right.$ and $\left.70^{\circ} \mathrm{C}\right)$ and drying time $(90,120$ and $150 \mathrm{~min})$. The first eight treatment combinations form a $2^{3}$ factorial design. The next six treatment combinations are referred to the axial runs, because they lie on the axes defined by the design variables. The last treatment combination represents the centre run and this arrangement of CCD as shown in Table 1 is in such a way that allows the development of the appropriate empirical equations (i.e., the second-order polynomial multiple regression equation) [6]. The model for predicting the quality of the green tea was expressed as:

$$
Y_{i}=\beta_{0}+\beta_{1} \mathrm{X}_{1}+\beta_{2} \mathrm{X}_{2}+\beta_{3} \mathrm{X}_{3}+\beta_{12} \mathrm{X}_{12}+\beta_{13} \mathrm{X}_{13}+\beta_{23} \mathrm{X}_{23}+\beta_{1}^{2} \mathrm{X}_{1}^{2}+\beta_{2}^{2} \mathrm{X}_{2}^{2}+\beta_{3}^{2} \mathrm{X}_{3}^{2}+\varepsilon_{i}
$$

*Corresonding author: Odunmbaku LA, Food Technology Department Moshood Abiola Polytechnic, Abeokuta, Nigeria, Tel: 08033868241; E-mail: ollypo2000@yahoo.com

Received September 14, 2015; Accepted September 29, 2015; Published October 07, 2015

Citation: Odunmbaku LA, Babajide JM, Shittu TA, Aroyeun SO, Eromosele CO et al. (2015) Effect of Process Variables on the Chemical Constituents and Sensory Characteristics of Nigerian Green Tea. J Food Process Technol 6: 510. doi:10.4172/2157-7110.1000510

Copyright: (C) 2015 Odunmbaku LA, et al. This is an open-access article distributed under the terms of the Creative Commons Attribution License, which permits unrestricted use, distribution, and reproduction in any medium, provided the original author and source are credited. 
Citation: Odunmbaku LA, Babajide JM, Shittu TA, Aroyeun SO, Eromosele CO, et al. (2015) Effect of Process Variables on the Chemical Constituents and Sensory Characteristics of Nigerian Green Tea. J Food Process Technol 6: 510. doi:10.4172/2157-7110.1000510

Page 2 of 7

\section{Chemical standard}

Epigallocatechin gallate, epigallocatechin, epicatechin gallate and epicatechin standards were sourced from Sigma Aldrich Chemical Co. (USA); HPLC grade acetonitrile, ethyl acetate and methanol (Merck, Germany).

\section{Equipment}

Chromatography Acrodisc Syringe membrane Filters $(0.45 \mu \mathrm{m}$, $30 \mathrm{~mm}$ diameter), Agilent (Germany); Water Distiller, AC-L4 Model, Optic Ivymen System, Europe; Vortex Mixer; KMC-1300 v Model, Vision scientific Co. Ltd., Korea; Syringes (1, 2 and $5 \mathrm{~mL}$ ), Agary; Micro-pipette (200 and $1000 \mu \mathrm{L}$ ) Gilson, France; $5 \mathrm{~mL}$ Plain sample Bottles (Polypropylene); Porcelain Mortar and Pestle. Volumetric Flasks (10, 500 and $1000 \mathrm{~mL}$ ), Borosilicate, Technico, England. Beakers (250, 500 and $1000 \mathrm{~mL})$, Borosilicate, NAFCO, Nigeria; Digital Analytical Weighing Balance (Metler Toledo Instrument Company), North and South America; High Pressure Liquid Chromatography (HPLC), Agilent Technologies 1120 LC Compact series (Agilent), Germany and Japan. The system comprises a UV-Vis detector and an HP computer system. The HPLC column used was a ZORBAX SB C8

\begin{tabular}{|c|c|c|c|}
\hline & $\mathbf{S T}(\mathbf{s e c})$ & $\mathbf{D T}\left({ }^{\circ} \mathbf{C}\right)$ & Dt (min) \\
\hline $\mathbf{1}$ & -1 & -1 & -1 \\
\hline $\mathbf{2}$ & +1 & -1 & -1 \\
\hline $\mathbf{3}$ & -1 & +1 & -1 \\
\hline $\mathbf{4}$ & +1 & +1 & -1 \\
\hline $\mathbf{5}$ & -1 & -1 & +1 \\
\hline $\mathbf{6}$ & +1 & -1 & +1 \\
\hline $\mathbf{7}$ & -1 & +1 & +1 \\
\hline $\mathbf{8}$ & +1 & +1 & +1 \\
\hline $\mathbf{9}$ & -1 & 0 & 0 \\
\hline $\mathbf{1 0}$ & +1 & 0 & 0 \\
\hline $\mathbf{1 1}$ & 0 & -1 & 0 \\
\hline $\mathbf{1 2}$ & 0 & +1 & 0 \\
\hline $\mathbf{1 3}$ & 0 & 0 & -1 \\
\hline $\mathbf{1 4}$ & 0 & 0 & +1 \\
\hline $\mathbf{1 5}$ & 0 & 0 & 0 \\
\hline
\end{tabular}

ST; steaming time, DT; Drying temperature, Dt; Drying time

Table 1: Experimental Runs of Optimized green tea sample.
$(75 \times 4.6 \mathrm{~mm}, 3.5 \mu \mathrm{m})$ from (Hewlet Packard, HP). Data acquisition was done with Chemstation Software.

\section{Determination of chemical constituents}

High-Performance Liquid Chromatography (HPLC) methods was used to determine the amount of epigallocatechin gallate (EGCG), epigallocatechin (EGC), epicatechin gallate (ECG) and epicatechin (EC) present in the green tea $[7,8]$. Grounded green tea samples were extracted using Methanol and distilled water (95:5\%) for $40 \mathrm{~min}$ at room temperature [9]. Solutions were filtered using a Millipore filter of $0.45 \mu \mathrm{m}$ size. Filtered samples were filled into a vial bottles and 20 $\mu \mathrm{l}$ each programmed for injection twice per sample for HPLC auto sampler analysis. Detection was carried out by measurement of UV absorbance at $270 \mathrm{~nm}$. Stock solutions of EGCG, EGC, ECG and EC were prepared by dissolving reference standards into mobile phase. Less concentrated solutions were prepared, as required, by dilution in the same mobile phase.

\section{Sensory evaluation}

Sensory attributes of the green tea infusion (Colour, Clearness, Dry Leaf Aroma, Green Tea Aroma, Sweetness, Bitterness, Green Tea Flavour and Astringency) were evaluated by semi trained panel $(n=25)$ using descriptive analysis [10]. Attribute intensities were rated on a scale of 1-9 with 1 representing lowest intensity value and 9 representing highest intensity value. The samples were presented to the panellists in random order as coded samples out of tea cups covered by lids. This was prepared $30 \mathrm{~min}$ before evaluation. Water was provided for cleansing the palate between the samples.

\section{Data analysis}

The results were subjected to analysis of variance using SPSS 16b statistical package. The means were used to calculate linear regressions between individual Catechin and sensory evaluations responses using MATLAB R2012a.

\section{Results}

As presented in Table 2, the EGCG content of green tea samples ranged from $46.90-178 \mathrm{mg} / \mathrm{g}$, EGC, $0.30-4.24 \mathrm{mg} / \mathrm{g}$; EC, $1.03-8.83$ $\mathrm{mg} / \mathrm{g}$ and ECG, $8.05-33.96 \mathrm{mg} / \mathrm{g}$. Table 3 showed the regression model result of the expected response against the observed responses. The

\begin{tabular}{|c|c|c|c|c|c|c|c|}
\hline Sample & ST time (Sec) & $\mathrm{DT}\left({ }^{\circ} \mathrm{C}\right)$ & D time (Min) & EGCG & EGC & EC & ECG \\
\hline 621 & 60 & 60 & 90 & $106.75 \pm 0.00^{d}$ & $0.95 \pm 0.00^{\mathrm{de}}$ & $3.08 \pm 0.40^{\text {ef }}$ & $11.29 \pm 0.50^{h}$ \\
\hline 738 & 60 & 70 & 90 & $112.45 \pm 1.20^{c}$ & $0.62 \pm 0.30^{e}$ & $2.21 \pm 0.18^{f}$ & $10.64 \pm 0.64^{h}$ \\
\hline 926 & 60 & 60 & 150 & $145.67 \pm 0.68^{b}$ & $0.30 \pm 0.06^{e}$ & $2.10 \pm 0.17^{f}$ & $8.60 \pm 0.24^{i}$ \\
\hline 194 & 60 & 70 & 150 & $178.06 \pm 0.17^{a}$ & $1.03 \pm 0.13^{\mathrm{de}}$ & $1.03 \pm 0.41^{g}$ & $8.05 \pm 0.19^{i}$ \\
\hline 531 & 60 & 65 & 120 & $112.05 \pm 0.49^{c}$ & $0.79 \pm 0.00^{\text {de }}$ & $2.61 \pm 0.94$ ef & $11.11 \pm 0.16^{h}$ \\
\hline 756 & 90 & 60 & 120 & $77.25 \pm 0.24^{i}$ & $2.82 \pm 0.93^{\mathrm{bc}}$ & $6.10 \pm 0.49^{c}$ & $17.99 \pm 1.01^{d}$ \\
\hline 573 & 90 & 70 & 120 & $91.94 \pm 1.01^{f}$ & $1.88 \pm 1.01^{\mathrm{cd}}$ & $3.36 \pm 0.07^{e}$ & $14.15 \pm 0.31^{f}$ \\
\hline 980 & 90 & 65 & 90 & $96.95 \pm 0.82^{\mathrm{e}}$ & $0.95 \pm 0.02^{\mathrm{de}}$ & $3.27 \pm 0.76^{e}$ & $12.77 \pm 0.50^{g}$ \\
\hline 292 & 90 & 65 & 150 & $90.74 \pm 0.49^{g}$ & $2.46 \pm 0.36^{c}$ & $4.49 \pm 0.31^{d}$ & $14.26 \pm 0.76^{f}$ \\
\hline 430 & 90 & 65 & 120 & $80.07 \pm 0.14^{h}$ & $2.50 \pm 0.50^{c}$ & $4.71 \pm 0.17^{d}$ & $16.13 \pm 0.11^{\mathrm{e}}$ \\
\hline 658 & 120 & 60 & 90 & $46.90 \pm 0.17^{\mathrm{m}}$ & $3.88 \pm 1.06^{\mathrm{ab}}$ & $1.04 \pm 0.05^{\mathrm{a}}$ & $33.96 \pm 0.09^{a}$ \\
\hline 271 & 120 & 70 & 90 & $72.51 \pm 0.59^{j}$ & $3.68 \pm 0.16^{\mathrm{ab}}$ & $6.11 \pm 0.68^{c}$ & $19.72 \pm 1.26^{c}$ \\
\hline 321 & 120 & 60 & 150 & $50.68 \pm 0.00^{\prime}$ & $4.24 \pm 0.17^{\mathrm{a}}$ & $8.83 \pm 0.00^{b}$ & $24.32 \pm 0.13^{b}$ \\
\hline 564 & 120 & 70 & 150 & $72.22 \pm 0.16^{j}$ & $3.72 \pm 0.24^{\mathrm{ab}}$ & $6.39 \pm 0.50^{c}$ & $23.55 \pm 0.44^{b}$ \\
\hline 250 & 120 & 65 & 120 & $70.05 \pm 0.03^{k}$ & $3.99 \pm 0.38^{a}$ & $8.40 \pm 0.33^{b}$ & $23.78 \pm 0.34^{b}$ \\
\hline
\end{tabular}

Values in the same column with same superscript are not significantly different at $P \leq 0.05$.

Table 2: Green tea Polyphenol content $(\mathrm{mg} / \mathrm{g})$ 
Citation: Odunmbaku LA, Babajide JM, Shittu TA, Aroyeun SO, Eromosele CO, et al. (2015) Effect of Process Variables on the Chemical Constituents and Sensory Characteristics of Nigerian Green Tea. J Food Process Technol 6: 510. doi:10.4172/2157-7110.1000510

Page 3 of 7

\begin{tabular}{|c|c|c|c|c|c|c|c|c|c|c|c|}
\hline ST (Sec) & $\mathbf{D T}\left({ }^{\circ} \mathbf{C}\right)$ & $\mathbf{D t}(\mathbf{m i n})$ & $\begin{array}{c}\text { EGCG } \\
\text { Measured }\end{array}$ & $\begin{array}{c}\text { EGCG } \\
\text { Predicted }\end{array}$ & $\begin{array}{c}\text { EGC } \\
\text { Measured }\end{array}$ & $\begin{array}{c}\text { EGC } \\
\text { Predicted }\end{array}$ & EC Measured & EC Predicted & $\begin{array}{c}\text { ECG } \\
\text { Measured }\end{array}$ & $\begin{array}{c}\text { ECG } \\
\text { Predicted }\end{array}$ & MSE \\
\hline 90 & 60 & 120 & 77.25 & 73.75 & 2.82 & 2.56 & 6.10 & 5.90 & 18.00 & 18.30 & 2.52 \\
\hline 120 & 60 & 90 & 46.90 & 58.53 & 3.88 & 3.98 & 10.37 & 9.97 & 33.96 & 31.37 & 28.45 \\
\hline 60 & 60 & 90 & 106.75 & 103.94 & 0.95 & 0.70 & 3.08 & 3.18 & 11.29 & 12.73 & 2.06 \\
\hline 60 & 70 & 90 & 112.45 & 115.76 & 0.62 & 0.54 & 2.21 & 1.68 & 10.64 & 8.82 & 3.11 \\
\hline 120 & 70 & 90 & 72.51 & 74.83 & 3.68 & 3.25 & 6.11 & 6.09 & 19.72 & 20.57 & 1.29 \\
\hline 60 & 60 & 150 & 145.67 & 143.84 & 0.30 & 0.68 & 2.10 & 2.11 & 8.60 & 7.63 & 0.92 \\
\hline 120 & 60 & 150 & 50.68 & 47.86 & 4.24 & 4.29 & 8.83 & 9.34 & 24.32 & 26.00 & 2.39 \\
\hline 90 & 65 & 150 & 90.74 & 102.91 & 2.46 & 1.96 & 4.49 & 3.69 & 14.26 & 12.85 & 30.21 \\
\hline 60 & 65 & 120 & 112.05 & 124.19 & 0.79 & 0.88 & 2.61 & 2.63 & 11.11 & 10.16 & 29.67 \\
\hline 120 & 70 & 150 & 72.22 & 75.53 & 3.72 & 3.93 & 6.39 & 6.27 & 23.55 & 21.98 & 2.74 \\
\hline 90 & 70 & 120 & 178.06 & 167.02 & 1.03 & 0.90 & 1.03 & 1.42 & 8.05 & 10.49 & 25.64 \\
\hline 120 & 65 & 120 & 70.05 & 55.74 & 3.99 & 4.04 & 8.40 & 8.44 & 23.78 & 25.22 & 41.40 \\
\hline 90 & 65 & 90 & 96.95 & 82.61 & 0.95 & 1.63 & 3.27 & 4.13 & 12.79 & 14.70 & 42.15 \\
\hline 60 & 70 & 150 & 91.94 & 93.49 & 1.88 & 2.30 & 3.36 & 3.62 & 14.15 & 14.33 & 0.57 \\
\hline 90 & 65 & 120 & 80.07 & 83.96 & 2.50 & 2.20 & 4.71 & 4.60 & 16.13 & 15.17 & 3.25 \\
\hline
\end{tabular}

Table 3: Polyphenol Regression model (mg/g).

\begin{tabular}{|c|c|c|c|c|c|c|c|c|c|c|c|}
\hline Sample Code & ST & DT & Dt & Greenness & Sweetness & Bitterness & Astringency & Clearness & DL Aroma & GT Aroma & GT Flavour \\
\hline 756 & 90 & 60 & 120 & $5.77 \pm 0.57^{\mathrm{bc}}$ & $1.17 \pm 0.38^{\mathrm{bc}}$ & $5.07 \pm 0.87^{c}$ & $2.20 \pm 0.41^{\mathrm{b}}$ & $5.80 \pm 0.48^{b}$ & $2.83 \pm 0.97^{d}$ & $2.27 \pm 0.45^{b}$ & $6.87 \pm 0.35^{b}$ \\
\hline 658 & 120 & 60 & 90 & $8.10 \pm 0.48^{a}$ & $1.00 \pm 0.00^{\circ}$ & $8.03 \pm 0.46^{a}$ & $1.00 \pm 0.00^{a}$ & $3.90 \pm 0.55^{c}$ & $1.87 \pm 0.35^{\mathrm{e}}$ & $1.07 \pm 0.25^{d}$ & $8.07 \pm 0.25^{a}$ \\
\hline 621 & 60 & 60 & 90 & $3.90 \pm 0.40^{\mathrm{d}}$ & $2.10 \pm 0.31^{a}$ & $4.10 \pm 0.40^{d}$ & $4.10 \pm 0.48^{c}$ & $7.83 \pm 0.53^{a}$ & $5.97 \pm 0.56^{a}$ & $4.17 \pm 0.38^{a}$ & $4.77 \pm 0.50^{c}$ \\
\hline 738 & 60 & 70 & 90 & $3.97 \pm 0.41^{\mathrm{d}}$ & $1.03 \pm 0.18^{\mathrm{bc}}$ & $4.17 \pm 0.46^{d}$ & $4.00 \pm 0.46^{a}$ & $7.97 \pm 0.49^{a}$ & $2.03 \pm 0.49^{e}$ & $1.07 \pm 0.25^{d}$ & $8.13 \pm 0.43^{a}$ \\
\hline 321 & 120 & 60 & 150 & $8.03 \pm 0.41^{\mathrm{a}}$ & $1.00 \pm 0.00^{c}$ & $4.20 \pm 0.41^{d}$ & $1.20 \pm 0.55^{a}$ & $3.93 \pm 0.52^{c}$ & $2.13 \pm 0.57^{e}$ & $1.20 \pm 0.41^{d}$ & $8.13 \pm 0.43^{a}$ \\
\hline 926 & 60 & 60 & 150 & $4.03 \pm 0.49^{d}$ & $1.20 \pm 0.41^{b}$ & $6.90 \pm 0.31^{b}$ & $4.20 \pm 0.41^{b}$ & $7.90 \pm 0.61^{a}$ & $1.93 \pm 0.37^{e}$ & $2.10 \pm 0.31^{b c}$ & $6.80 \pm 0.48^{b}$ \\
\hline 271 & 120 & 70 & 90 & $8.03 \pm 0.41^{a}$ & $2.20 \pm 0.41^{a}$ & $8.00 \pm 0.37^{a}$ & $1.10 \pm 0.31^{c}$ & $3.93 \pm 0.45^{c}$ & $5.67 \pm 0.71^{b}$ & $4.17 \pm 0.38^{a}$ & $4.77 \pm 0.50^{c}$ \\
\hline 292 & 90 & 65 & 150 & $6.00 \pm 0.26^{b}$ & $1.13 \pm 0.35^{\mathrm{bc}}$ & $7.10 \pm 0.31^{\mathrm{b}}$ & $2.10 \pm 0.40^{\mathrm{b}}$ & $5.80 \pm 0.55^{b}$ & $2.77 \pm 0.50^{d}$ & $2.17 \pm 0.38^{b c}$ & $6.77 \pm 0.43^{b}$ \\
\hline 531 & 60 & 65 & 120 & $3.97 \pm 0.49^{d}$ & $1.00 \pm 0.00^{c}$ & $4.17 \pm 0.38^{d}$ & $4.13 \pm 0.43^{a}$ & $7.83 \pm 0.59^{a}$ & $2.13 \pm 0.43^{e}$ & $1.07 \pm 0.25^{d}$ & $8.07 \pm 0.37^{a}$ \\
\hline 564 & 120 & 70 & 150 & $8.03 \pm 0.49^{a}$ & $2.13 \pm 0.35^{\mathrm{a}}$ & $8.00 \pm 0.37^{a}$ & $1.17 \pm 0.46^{c}$ & $3.90 \pm 0.40^{c}$ & $5.93 \pm 0.37^{\mathrm{ab}}$ & $4.20 \pm 0.48^{\mathrm{a}}$ & $4.93 \pm 0.45^{c}$ \\
\hline 430 & 90 & 65 & 120 & $5.87 \pm 0.43^{\mathrm{bc}}$ & $2.23 \pm 0.43^{\mathrm{a}}$ & $7.97 \pm 0.18^{a}$ & $2.23 \pm 0.68^{c}$ & $6.00 \pm 0.37^{b}$ & $5.90 \pm 0.40^{\mathrm{ab}}$ & $4.17 \pm 0.46^{\mathrm{a}}$ & $4.83 \pm 0.46^{c}$ \\
\hline 250 & 120 & 65 & 120 & $8.00 \pm 0.52^{\mathrm{a}}$ & $1.00 \pm 0.00^{c}$ & $8.00 \pm 0.41^{a}$ & $1.27 \pm 0.58^{a}$ & $3.87 \pm 0.51^{c}$ & $2.13 \pm 0.35^{e}$ & $1.20 \pm 0.48^{d}$ & $8.27 \pm 0.45^{a}$ \\
\hline 980 & 90 & 65 & 90 & $5.70 \pm 0.47^{c}$ & $1.13 \pm 0.35^{b c}$ & $6.87 \pm 0.35^{b}$ & $2.20 \pm 0.41^{b}$ & $5.77 \pm 0.63^{b}$ & $2.93 \pm 0.52^{\text {cd }}$ & $2.23 \pm 0.57^{b c}$ & $6.83 \pm 0.38^{b}$ \\
\hline 194 & 60 & 70 & 150 & $4.00 \pm 0.64^{\mathrm{d}}$ & $2.17 \pm 0.38^{a}$ & $4.13 \pm 0.35^{d}$ & $4.23 \pm 0.43^{c}$ & $7.97 \pm 0.49^{a}$ & $5.73 \pm 0.52^{\mathrm{ab}}$ & $4.17 \pm 0.38^{a}$ & $4.77 \pm 0.57^{c}$ \\
\hline 573 & 90 & 70 & 120 & $5.87 \pm 0.43^{b c}$ & $1.17 \pm 0.38^{b c}$ & $7.00 \pm 0.37^{b}$ & $2.37 \pm 1.03^{b}$ & $5.83 \pm 0.53^{b}$ & $3.13 \pm 0.43^{c}$ & $2.03 \pm 0.18^{c}$ & $6.87 \pm 0.51^{b}$ \\
\hline
\end{tabular}

Values in the same column with same superscript are not significantly different at $P \leq 0.05$.

Table 4: Descriptive sensory evaluation mean scores of green tea samples.

regression coefficients $\left(\mathrm{r}^{2}\right)$ for EGCG, EGC, EC and ECG were 0.931 , $0.939,0.976$ and 0.943 respectively. Descriptive sensory attributes of the green tea samples as affected by steaming time, drying temperature and drying time were presented in Tables 4 and 5 . The result shows that green colour attribute ranged between 3.90 and 8.10 , sweetness ranged between 1.00 and 2.23, bitterness ranged between 4.0 and 8.23 while astringency ranged between 1.00 and 4.23 . Clearness ranged between 3.87 and 7.97, dried leaf aroma ranged between 1.87 and 5.97 while GT aroma and flavour ranged from 1.07 to 4.20 and 4.77 to 8.27 respectively. Chromatogram of NGT chemical constituent and the effect of the steaming time, drying temperature and drying time on the EGCG content and sensory characteristics of optimized green teas were presented in Figures 1 and 2 respectively. The predicted models for the optimization of chemical constituents and sensory attributes of Nigerian green tea are presented in Tables 6 and 7.

\section{Discussion}

From the results, there were significant differences $(\mathrm{P} \leq 0.05)$ in the chemical constituents and sensory attributes of the optimized Green tea samples. It was observed that, steaming for shorter period of time resulted in higher EGCG content compared with longer steaming duration. $\mathrm{Xu}$ and Chen [11] reported that gallated catechins usually convert into non-gallated catechins through hydrolysis under humid and heating conditions. Gulati [12] also reported that the chemical content and the composition of green tea catechins may vary with the conditions of processing. Reduction in the EGCG content at longer steaming duration therefore could be as a result of the release of EGC from EGCG.

The predictive model result for epigallocatechin gallate (EGCG) revealed that, increase in the steaming time, drying temperature, drying time and the product effect of the "steaming time and drying time" brings about a reduction in the amount of EGCG content. Increase in the product effect of the "steaming time and drying temperature", "drying temperature and drying time", quadratic effect of the steaming time as well as the quadratic effect of drying time positively enhances the EGCG content. The correlation coefficient $\mathrm{R}$ value was estimates to be 0.965 . This indicates that there is a strong positive relationship between the EGCG and the independent variables.

The epigallocatechin (EGC) content increases with unit increase the in steaming time, drying time, product effect of the "steaming time and drying time", "drying temperature and drying time", quadratic effect of the steaming time and drying temperature while increase in 
Citation: Odunmbaku LA, Babajide JM, Shittu TA, Aroyeun SO, Eromosele CO, et al. (2015) Effect of Process Variables on the Chemical Constituents and Sensory Characteristics of Nigerian Green Tea. J Food Process Technol 6: 510. doi:10.4172/2157-7110.1000510

Page 4 of 7

\begin{tabular}{|c|c|c|c|c|}
\hline Parameters & Predicted model & RMSE & $R^{2}$ & $P$-value \\
\hline EGCG & $y_{i}=193.61-1.1407 x_{1}+0.8295 x_{2}-1.9733 x_{3}+0.0074685\left(x_{1} x_{2}\right)-0.014046 \beta_{13}\left(x_{1} x_{3}\right)+0.018927\left(x_{2} x_{3}\right)+0.006666 x_{1}^{2}$ & 15.2 & 0.931 & 0.0198 \\
\hline EGC & $y_{i}=33101+005159 x_{1}-11996 x_{2}+0065013 x_{3}-000095174\left(x_{1} x_{2}\right)+89843 e^{(-05)} ?_{1} 3\left(x_{1} x_{3}\right)+000062478\left(x_{2} x_{3}\right)+000028963 x_{1}^{2}+00091122 x_{2}^{2}-000045081 x_{3}^{2}$ & 0.585 & 0.939 & 0.0148 \\
\hline EC & $y_{i}=24593+015247 x_{1}-0861 x_{2}+0077131 x_{3}-00039647\left(x_{1} x_{2}\right)+000012372 ?_{1} 3\left(x_{1} x_{3}\right)+00013472\left(x_{2} x_{3}\right)+00010407 x_{1}^{2}+00063686 x_{2}^{2}-000076346 x_{3}^{2}$ & 0.719 & 0.976 & 0.0016 \\
\hline ECG & $y_{i}=23657+050076 x_{1}-66859 x_{2}-0386611 x_{3}-0011475\left(x_{1} x_{2}\right)-72518 e^{(-05)} ?_{1} 3\left(x_{1} x_{3}\right)+0011283\left(x_{2} x_{3}\right)+00028049 x_{1}^{2}+0045906 x_{2}^{2}-00015459 x_{3}^{2}$ & 2.87 & 0.943 & 0.0123 \\
\hline Colour & $y_{i}=-1.1278+0.046081 x_{1}+0.053789 x_{2}-0.00049034 x_{3}-9.1084 e^{-05}\left(x_{1} x_{2}\right)-3.1885 e^{-05} \beta_{13}\left(x_{1} x_{3}\right)-2.5386 e^{-05}\left(x_{2} x_{3}\right)+0.00017436 x_{1}^{2}-0.00031591 x_{2}^{2}+2.6196 e^{-05} x_{3}^{2}$ & 0.094 & 0.999 & $7.06 \mathrm{e}^{-07}$ \\
\hline clearness & $y_{i}=0.5076+0.063381 x_{1}-0.049555 x_{2}+0.017627 x_{3}-0.000134\left(x_{1} x_{2}\right)-1.3921 e^{-05} \beta_{13}\left(x_{1} x_{3}\right)-0.00019836\left(x_{2} x_{3}\right)+7.5381 e^{-05} x_{1}^{2}+0.00066464 x_{2}^{2}-1.464 e^{-05} x_{3}^{2}$ & 0.094 & 0.999 & $7.54 \mathrm{e}^{-07}$ \\
\hline $\begin{array}{l}\text { Dried Leaf } \\
\text { Aroma }\end{array}$ & $y_{i}=32.308-0.22121 x_{1}-0.56524 x_{2}+0.02394 x_{3}-0.00035837\left(x_{1} x_{2}\right)-5.1348 e^{-05} \beta_{13}\left(x_{1} x_{3}\right)-0.00024031\left(x_{2} x_{3}\right)+0.0010424 x_{1}^{2}+0.0048981 x_{2}^{2}-1.5324 e^{-05} x_{3}^{2}$ & 0.178 & 0.996 & $1.92 \mathrm{e}^{-05}$ \\
\hline $\begin{array}{l}\text { Green Tea } \\
\text { Aroma }\end{array}$ & $y_{i}=12.56-0.1406 x_{1}-0.044293 x_{2}-0.0024466 x_{3}-2.526 e^{-05}\left(x_{1} x_{2}\right)-3.1978 e^{-05} \beta_{13}\left(x_{1} x_{3}\right)-2.526 e^{-05}\left(x_{2} x_{3}\right)+0.00052871 x_{1}^{2}+0.00035264 x_{2}^{2}+2.3157 e^{-05} x_{3}^{2}$ & 0.078 & 0.999 & $1.03 e^{-06}$ \\
\hline Sweetness & $y_{i}=9.125-0.11677 x_{1}-0.055922 x_{2}+0.0010414 x_{3}+0.00019096\left(x_{1} x_{2}\right)+4.0746 e^{-06} \beta_{13}\left(x_{1} x_{3}\right)-2.4558 e^{-05}\left(x_{2} x_{3}\right)+0.00046961 x_{1}^{2}+0.0002948 x_{2}^{2}+2.1918 e^{-06} x_{3}^{2}$ & 0.032 & 0.999 & $1.01 \mathrm{e}^{-06}$ \\
\hline Bitterness & $y_{i}=4.1628+0.23717 x_{1}-0.37469 x_{2}+0.026199 x_{3}+8.341 e^{-05}\left(x_{1} x_{2}\right)+2.2227 e^{-05} \beta_{13}\left(x_{1} x_{3}\right)-8.3168 e^{-05}\left(x_{2} x_{3}\right)-0.0010064 x_{1}^{2}+0.0028732 x_{2}^{2}-9.5125 e^{-05} x_{3}^{2}$ & 0.567 & 0.961 & 0.00495 \\
\hline $\begin{array}{l}\text { Green Tea } \\
\text { Flavour }\end{array}$ & $y_{i}=8.5731+0.14363 x_{1}-0.32556 x_{2}-0.0015971 x_{3}-0.00015029\left(x_{1} x_{2}\right)-1.3888 e^{-05} \beta_{13}\left(x_{1} x_{3}\right)-1.6506 e^{-05}\left(x_{2} x_{3}\right)-0.00042705 x_{1}^{2}+0.0026267 x_{2}^{2}+1.1808 e^{-05} x_{3}^{2}$ & 0.075 & 0.999 & $5.76 e^{-07}$ \\
\hline Astringency & $y_{i}=5.0908-0.15651 x_{1}+0.16684 x_{2}+0.015398 x_{3}+0.00011728\left(x_{1} x_{2}\right)-8.2575 e^{-06} \beta_{13}\left(x_{1} x_{3}\right)-4.8924 e^{-07}\left(x_{2} x_{3}\right)+0.00055648 x_{1}^{2}-0.0013763 x_{2}^{2}-5.4016 e^{-05} x_{3}^{2}$ & 0.101 & 0.998 & $4.23 e^{-06}$ \\
\hline
\end{tabular}

$x_{1}$, Steaming time; $x_{2}$, Drying temperature; $x_{3}$ Drying time.

Table 5: Regression Models of Polyphenols Content and Sensory Acceptance of Green tea.

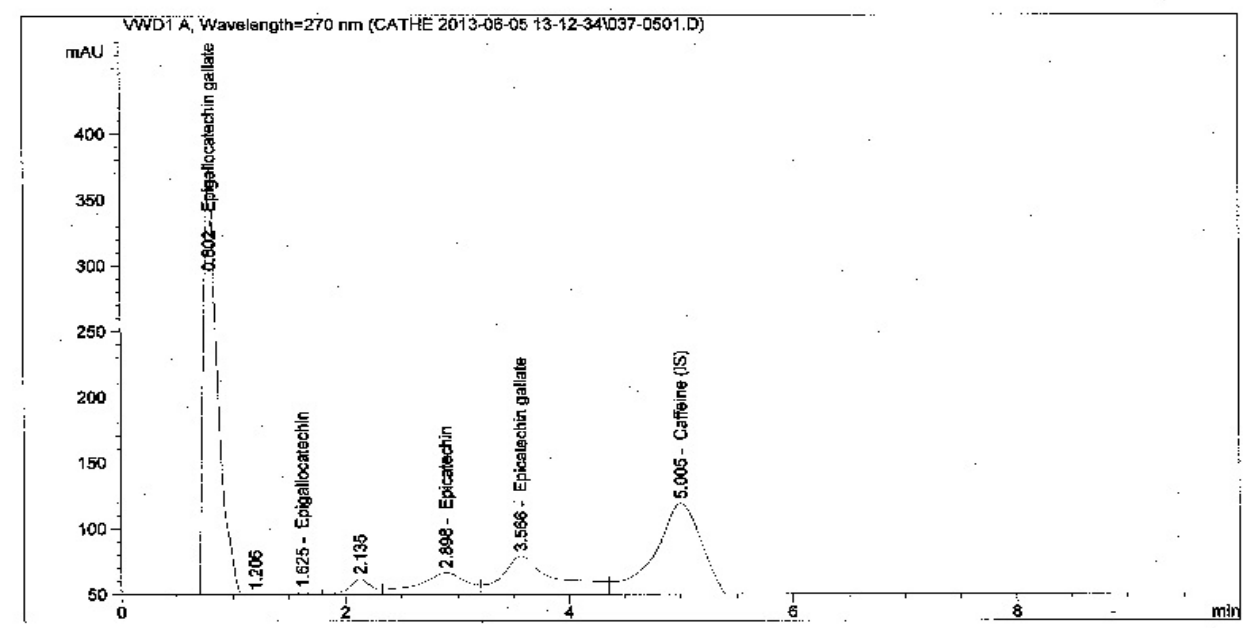

Figure 1: The Chromatogram of Nigerian green tea catechin.

drying temperature, product effect of the "steaming time and drying temperature" and quadratic effect of the drying time brings about a reduction in the amount of EGC content. The correlation coefficient value was estimated to be 0.969 . This indicates that there is a strong positive relationship between EGC content and the independent variables.

The Epicatechin (EC) content, increases with unit increase in steaming time, drying time, product effect of the "steaming time and drying time", "drying temperature and drying time", quadratic effect of the steaming time as well as the quadratic effect of drying temperature. Increase in drying temperature, the product effect of the "steaming time and drying temperature" and quadratic effect of the drying time brings about a reduction in the amount of EC content. Strong positive relationship exists between the EC content and the independent variables.
Epicatechin gallate (ECG) increases with unit increase steaming time, product effect of the "drying temperature and drying time", quadratic effect of the steaming time and quadratic effect of the drying temperature while increase in drying temperature, drying time, product effect of the "steaming time and drying temperature", "steaming time and drying time" and quadratic effect of the drying time brings about a reduction in the amount of ECG content. The estimated correlation coefficient value of 0.971 indicates that there is a strong positive relationship between the amount of ECG content and the independent variables.

Somkiat [13] reported that colour is an important indicator for the quality of processed tea. The predictive model for the green colour intensity of green tea revealed that increase in steaming time and drying temperature brings about an increase in the green colour intensity of the tea extract while unit increase in drying time reduces the green colour intensity. The product effect of the "steaming time 

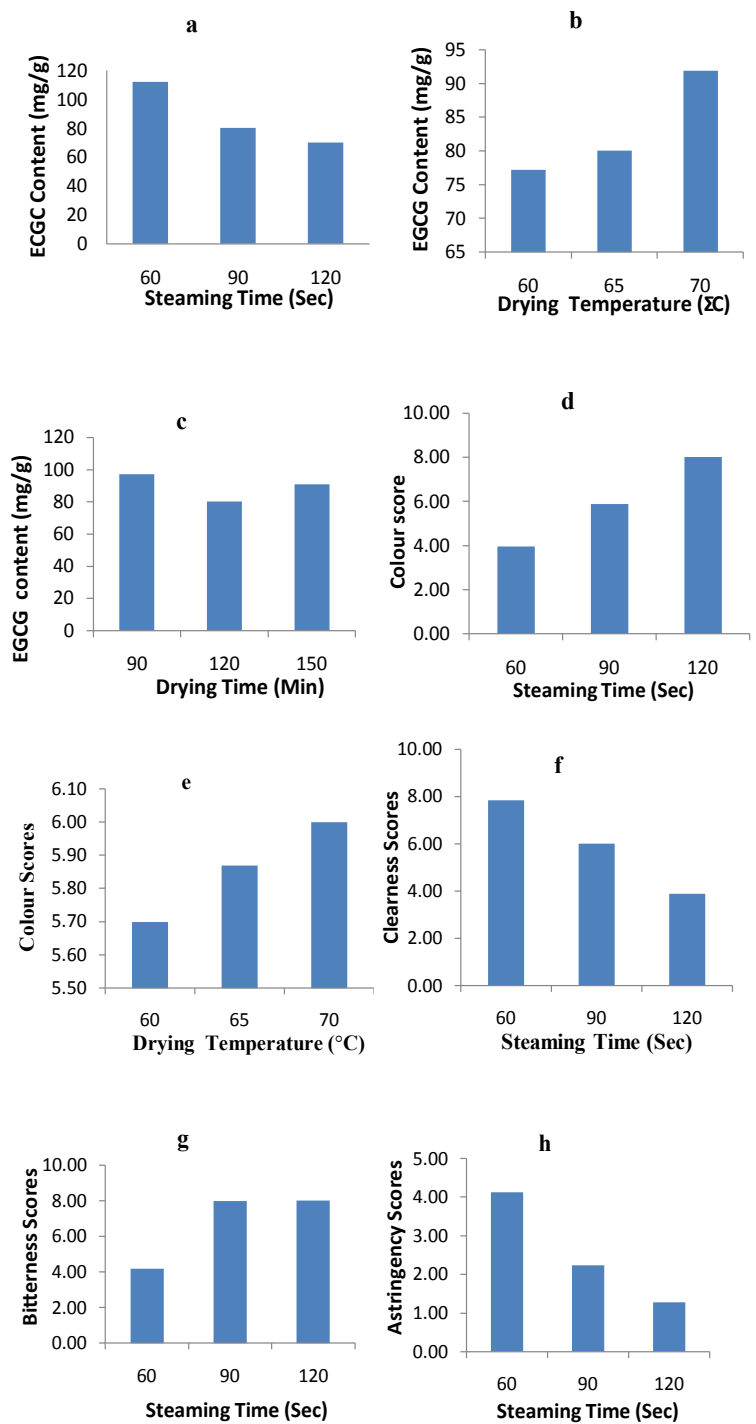

Figure 2: Effect of process variables on EGCG and sensory characteristic of NGT. and drying temperature", "steaming time and drying time" and "drying temperature and drying time" also brings about a reduction in the green colour intensity. The quadratic effect of the steaming and drying time brings about an increase in the colour intensity of the green tea extract while the quadratic effect of the drying temperature leads to a reduction in the colour intensity. There exist a strong positive relationship between the green colour intensity and the independent variables. However, for the nine explanatory variables studied, only the quadratic effect of the steaming time exerts significant influence ( $\mathrm{r}=$ $0.99, \mathrm{p}=0.044629)$ on the green colour intensity of the tea extract.

Sample steamed for $120 \mathrm{sec}$, dried at $60^{\circ} \mathrm{C}$ for $90 \mathrm{~min}$. was the most preferable based on green colour intensity. Sample 658 has the highest colour score $(8.10)$ which was not significantly different $(\mathrm{P} \leq 0.05)$ from samples 564 (8.03), 321 (8.03), 271 (8.03) and 250 (8.00). Green colour intensity of this samples were significant different $(\mathrm{P} \leq 0.05)$ from those of all other samples, however, the least scores were recorded in samples 926 (4.03), 194 (4.00), 531 (3.97), 738 (3.97) and 621(3.90) in that order.

Unit increase in the steaming time, drying temperature as well as the product effect of "drying temperature and drying time" brings about a reduction in the sweetness of the green tea extract while increase in the drying duration as well as the product effect of the "steaming time and drying temperature", "steaming time and drying time", quadratic effect of the steaming time, drying temperature and drying time enhances the sweetness. A strong positive relationship exists between the sweetness of the green tea extract and the independent variables. However, for the nine explanatory variables studied, only the steaming time, product effect of the "steaming time and drying temperature" and the quadratic effect of the steaming time, exert significant influence on the sweetness $\left(\mathrm{r}=0.999, p=9.1011 \mathrm{e}^{-06}, 0.049795\right.$ and $\left.4.0076 \mathrm{e}^{-06}\right)$. All samples taste attributes for sweetness were weak and therefore recorded low mean scores as recorded in sample 531, 250, 658 and 321 (1.00). Sample 430 had the highest sweetness mean score (2.23).

The predictive model for Bitterness indicates that, every unit increase in the steaming time as well as the drying duration, product effect of the "steaming time and drying temperature", "steaming time and drying time" and quadratic effect of the drying temperature brings about an increase in the bitterness of the tea extract while the drying temperature, product effect of the "drying temperature and drying time", quadratic effect of the steaming time and quadratic effect of

\begin{tabular}{|c|c|c|c|c|c|c|c|c|c|c|c|}
\hline $\begin{array}{l}\text { ST } \\
\text { sec }\end{array}$ & $\begin{array}{l}\text { DT } \\
{ }^{\circ} \mathrm{C}\end{array}$ & $\begin{array}{c}\mathrm{Dt} \\
\min \end{array}$ & $\begin{array}{c}\text { Colour } \\
\text { (Measured) }\end{array}$ & $\begin{array}{c}\text { Colour } \\
\text { (Predicted) }\end{array}$ & $\begin{array}{l}\text { Sweetness } \\
\text { (Measured) }\end{array}$ & $\begin{array}{l}\text { Sweetness } \\
\text { (Predicted) }\end{array}$ & $\begin{array}{l}\text { Bitterness } \\
\text { (Measured) }\end{array}$ & $\begin{array}{l}\text { Bitterness } \\
\text { (Predicted) }\end{array}$ & $\begin{array}{c}\text { Astringency } \\
\text { (Measured) }\end{array}$ & $\begin{array}{l}\text { Astringency } \\
\text { (Predicted) }\end{array}$ & MSE \\
\hline 90 & 60 & 120 & 5.77 & 6.12 & 1.17 & 1.01 & 4.13 & 5.94 & 2.20 & 1.86 & 0.91 \\
\hline 120 & 65 & 120 & 8.10 & 7.98 & 1.00 & 1.02 & 7.97 & 8.01 & 1.00 & 1.13 & 0.01 \\
\hline 60 & 60 & 90 & 3.90 & 3.91 & 2.20 & 2.22 & 4.20 & 3.85 & 4.10 & 4.15 & 0.03 \\
\hline 60 & 65 & 120 & 3.97 & 4.32 & 2.13 & 2.00 & 4.17 & 4.73 & 4.00 & 3.69 & 0.16 \\
\hline 120 & 60 & 150 & 8.03 & 8.39 & 1.00 & 0.84 & 8.00 & 8.20 & 1.10 & 0.75 & 0.10 \\
\hline 60 & 70 & 90 & 4.03 & 3.60 & 2.23 & 2.42 & 4.17 & 3.82 & 4.20 & 4.60 & 0.15 \\
\hline 120 & 60 & 90 & 8.03 & 7.60 & 1.00 & 1.21 & 8.03 & 7.10 & 1.20 & 1.62 & 0.36 \\
\hline 60 & 60 & 150 & 6.00 & 5.70 & 1.20 & 1.30 & 6.90 & 6.28 & 2.10 & 2.34 & 0.16 \\
\hline 60 & 70 & 150 & 3.97 & 4.33 & 2.17 & 1.99 & 4.13 & 4.89 & 4.13 & 3.76 & 0.25 \\
\hline 120 & 70 & 150 & 8.03 & 7.97 & 1.03 & 1.04 & 8.00 & 8.20 & 1.17 & 1.17 & 0.01 \\
\hline 90 & 70 & 120 & 5.87 & 5.75 & 1.17 & 1.22 & 7.00 & 5.93 & 2.13 & 2.29 & 0.32 \\
\hline 120 & 70 & 90 & 8.00 & 8.24 & 1.00 & 0.93 & 8.00 & 8.46 & 1.27 & 1.08 & 0.10 \\
\hline 90 & 65 & 150 & 5.70 & 5.35 & 1.13 & 1.35 & 6.87 & 6.35 & 2.20 & 2.68 & 0.20 \\
\hline 90 & 65 & 90 & 4.00 & 4.59 & 2.10 & 1.75 & 4.10 & 5.26 & 4.23 & 3.55 & 0.63 \\
\hline 90 & 65 & 120 & 5.87 & 5.42 & 1.13 & 1.34 & 7.10 & 5.88 & 2.23 & 2.58 & 0.47 \\
\hline
\end{tabular}

Table 6: Regression results for the sensory attributes of Nigerian Green tea. 


\begin{tabular}{|c|c|c|c|c|c|c|c|c|c|c|c|}
\hline $\begin{array}{l}\text { S T } \\
\text { sec }\end{array}$ & $\begin{array}{l}\text { DT } \\
{ }^{\circ} \mathrm{C}\end{array}$ & $\begin{array}{c}\mathrm{Dt} \\
\mathrm{min}\end{array}$ & $\begin{array}{l}\text { Clearness } \\
\text { (Measured) }\end{array}$ & $\begin{array}{l}\text { Clearness } \\
\text { (Predicted) }\end{array}$ & \begin{tabular}{|c|} 
DLA \\
(Measured)
\end{tabular} & $\begin{array}{c}\text { DLA } \\
\text { (Predicted) }\end{array}$ & $\begin{array}{c}\text { GT A } \\
\text { (Measured) }\end{array}$ & \begin{tabular}{|c|} 
GT A \\
(Predicted)
\end{tabular} & \begin{tabular}{|c|} 
GT F \\
(Measured)
\end{tabular} & $\begin{array}{c}\text { GT F } \\
\text { (Predicted) }\end{array}$ & M SE \\
\hline 90 & 60 & 120 & 5.80 & 6.16 & 5.93 & 4.10 & 2.27 & 1.86 & 6.87 & 7.15 & 0.91 \\
\hline 120 & 65 & 120 & 7.90 & 7.86 & 2.13 & 2.27 & 1.20 & 1.26 & 8.27 & 8.14 & 0.01 \\
\hline 60 & 60 & 90 & 3.87 & 3.84 & 5.67 & 5.98 & 4.17 & 4.19 & 4.77 & 4.75 & 0.03 \\
\hline 60 & 65 & 120 & 3.93 & 4.24 & 5.93 & 5.24 & 4.20 & 3.90 & 4.93 & 5.23 & 0.16 \\
\hline 120 & 60 & 150 & 7.97 & 8.30 & 2.13 & 1.83 & 1.20 & 0.84 & 8.13 & 8.53 & 0.10 \\
\hline 60 & 70 & 90 & 3.90 & 3.50 & 5.90 & 6.34 & 4.17 & 4.59 & 4.83 & 4.39 & 0.15 \\
\hline 120 & 60 & 90 & 7.97 & 7.54 & 2.13 & 3.11 & 1.07 & 1.56 & 8.07 & 7.63 & 0.36 \\
\hline 60 & 60 & 150 & 5.80 & 5.56 & 1.93 & 2.68 & 2.10 & 2.38 & 6.80 & 6.57 & 0.16 \\
\hline 60 & 70 & 150 & 3.90 & 4.25 & 5.73 & 4.91 & 4.17 & 3.75 & 4.77 & 5.16 & 0.25 \\
\hline 120 & 70 & 150 & 7.83 & 7.79 & 2.03 & 1.85 & 1.07 & 1.11 & 8.13 & 8.11 & 0.01 \\
\hline 90 & 70 & 120 & 5.83 & 5.74 & 3.13 & 4.29 & 2.03 & 2.20 & 6.87 & 6.76 & 0.32 \\
\hline 120 & 70 & 90 & 7.83 & 8.00 & 1.87 & 1.27 & 1.07 & 0.85 & 8.07 & 8.26 & 0.10 \\
\hline 90 & 65 & 150 & 5.77 & 5.38 & 2.93 & 3.48 & 2.23 & 2.68 & 6.83 & 6.31 & 0.20 \\
\hline 90 & 65 & 90 & 3.93 & 4.62 & 5.97 & 4.84 & 4.17 & 3.46 & 4.77 & 5.48 & 0.63 \\
\hline 90 & 65 & 120 & 6.00 & 5.45 & 3.20 & 4.31 & 2.17 & 2.64 & 6.77 & 6.43 & 0.47 \\
\hline
\end{tabular}

Table 7: Regression for the sensory attributes of Nigerian Green tea.

the drying time, brings about a reduction in the bitterness. The result also indicated that there is a strong positive relationship between the bitter taste intensity and the independent variables. Sample 658 was rated highest in bitterness, followed by samples 250, 564, 271 and 430 . Sample 621 (4.10) had the lowest score for bitterness. This could be as a result of the short steaming period.

From the predictive model result for astringency, every unit increase in the steaming time, drying temperature, drying time, product effects of the "steaming time and drying temperature", "drying temperature and drying time" as well as the quadratic effect of the drying temperature and drying time brings about a reduction in the astringency of the tea extract. Increase in the quadratic effect of the steaming time brings about an increase in the astringency of the green tea extract. The correlation coefficient value was estimated to be 0.999 . This indicates that there is a strong positive relationship between astringency and the independent variables. However, for the nine explanatory variables studied, only the steaming time and quadratic effect of the steaming time exert significant influence on the astringency with $p$-Value of 0.0061525 for steaming time, and 0.00050398 for the quadratic effect of steaming time. Sample $194(4.23)$ was the most preferred in astringency followed by 926 (4.20), 531 (4.13) in that order. This finding agrees with Wismer [14] that astringency is an important and often appealing characteristic of brewed tea. Sample 658 had the lowest scores for astringency which was significantly different $(p \leq 0.05)$ from those of all other samples.

Unit increase in the steaming time, quadratic effects of the steaming time as well as drying temperature and drying duration brings about an increase in the clearness of the green tea extract while increase in drying temperature, product effect of the "steaming time and drying temperature", "steaming time and drying time", "drying temperature and drying time" and the quadratic effect of the drying time reduces the clarity of the green tea extract. A strong positive relationship exists between the clarity of the tea extract and the independent variables. However, for the nine explanatory variables studied, only the steaming time exerts significant influence on the clearness $(\mathrm{r}=0.999, p=0.0211)$. The highest clearness score was found in samples 738 (7.97), 194 (7.90), 531 (7.83) which had a better appearance attribute in terms of clarity. Steaming for a shorter period $(60 \mathrm{~s})$ could be attributed to the clarity of these samples. Sample 250 (3.87) was rate the least and significantly different $(\mathrm{P} \leq 0.05)$ from other samples.
Increase in steaming time, Drying time, quadratic effects of the steaming time and drying temperature, brings about a rise in the dried leaf aroma of the tea extract while increase in drying temperature, the product effect of the "steaming time and drying temperature", "steaming time and drying time" as well as "drying temperature and drying time" and the quadratic effect of the drying time brings about a reduction in the dried leaf aroma of the tea extract. The correlation coefficient $R$ value was estimated to be 0.998 . This indicates that there is a strong positive relationship between dried leaf aroma and the independent variables. However, for the nine explanatory variables studied, only the steaming time and the quadratic effect of the steaming time exert significant influence $(p=0.0017056$ and 0.00038171$)$ on the dried leaf aroma.

Steaming for a shorter period $(60 \mathrm{~s})$, drying at $60^{\circ} \mathrm{C}$ for 90 mins enhances the aroma of the green tea sample. The duration of the steaming process was said to be a key determinant in green tea flavour, aroma, and colour. Steamed leaves left at high temperature will lose their bright colour and their flavour and aroma will be negatively affected [15]. From the result for Green tea aroma (GTA), every unit increase in the steaming time, drying temperature, drying time, product effect of the "steaming time and drying temperature", "steaming time and drying time" as well as "drying temperature and drying time" brings about a reduction in the GTA while the quadratic effect of steaming time, drying temperature and time positively enhance the green tea aroma of the tea extract. Strong positive relationship exists between GTA and the independent variables however, for the nine explanatory variables studied, only the steaming time and the quadratic effect of the steaming time exerts significant influence $(\mathrm{r}=0.999, P=0.00029991$, 0.00018735) on the GTA.

Unit increase in the steaming time while the drying temperature, drying time, product effect of the steaming time and drying temperature; steaming time and drying time; drying temperature and drying time, and the quadratic effect of the steaming time; drying temperature; and drying time are kept constant brings about an increase in the green tea flavour while increase in drying temperature brings about a reduction in the green tea flavour. There is equally a negative relationship between the drying time and the green tea flavour. This indicates that increase in drying time will bring about a reduction in the green tea flavour. Furthermore, a negative relationship exists between the product effect of the "steaming time and drying temperature" as well as "steaming time 
Citation: Odunmbaku LA, Babajide JM, Shittu TA, Aroyeun SO, Eromosele CO, et al. (2015) Effect of Process Variables on the Chemical Constituents and Sensory Characteristics of Nigerian Green Tea. J Food Process Technol 6: 510. doi:10.4172/2157-7110.1000510

Page 7 of 7

and drying time" and the green tea flavour; this indicates that increase in this variable brings about a reduction in the green tea flavour. Increase in the quadratic effect of drying temperature and drying time however brings about an increase in the flavour of the tea extract. The correlation coefficient $R$ value for the green tea flavour was estimated to be 0.999 . This indicates that there is a strong positive relationship exists between the green tea flavour and the independent variables, however, for the nine explanatory variables studied, only the steaming time and quadratic effect of the steaming time exerts significant influence ( $p=0.00022153,0.00042252)$ on the green tea flavour.

\section{Conclusion}

There were significant differences $(\mathrm{P} \leq 0.05)$ among the optimized Green tea samples as influenced by the processing variables (steaming time, drying temperature and drying time). This study revealed that, steaming for shorter period of time resulted in higher EGCG content compared with longer steaming duration. Significant difference $(\mathrm{P} \leq$ 0.05) was also recorded in the EGC content of the optimized green tea samples. Steaming for longer period (120 s) positively enhanced the green colouration in green tea while shorter steaming regime $(60 \mathrm{~s})$ is desirable for clarity of green tea extract. Moderate steaming period $(90$ s) gives better aroma as the intensity of green tea aroma reduces with elongation of the steaming period. Astringency reduces with steaming time and this correlates with the Epigallocatechingalate (EGCG) content which is higher at minimum (60 s) steaming time.

Drying at higher temperature $\left(70^{\circ} \mathrm{C}\right)$ enhances the colour intensity of green tea while an average drying temperature of $60^{\circ} \mathrm{C}$ gives better clarity of the extract. More EGCG is recorded in green tea dried at $70^{\circ} \mathrm{C}$ than at lower temperature, this could possibly be as a result of higher drying rate at higher temperature. The intensity of green tea flavour gets more pronounced as the drying temperature increases.

\section{References}

1. Willson KC (1999) Coffee, Cocoa and Tea. New York: CABI Publishing.
2. McKay DL, Blumberg JB (2002) The role of tea in human health: An update. J Am Coll Nutr 21: 1-13.

3. Jung DH (2004) Components and Effects of Tea (In Korean) Hongikjae, Seoul, Korea. 28-43.

4. Banga JR, Balsa-Canto E, Moles CG, Alonso AA (2003) Improving Food Processing Using Modern Optimization Methods. Trends in Food Science and Technology 14: 131-144.

5. Hakim IA, Weisgerber UM, Harris RB, Balentine D, van-Mierlo CAJ, et al. (2000) Preparation, composition and consumption patterns of tea-based beverages in Arizona. Nutrition Research 20: 1715-1724.

6. Mason RL, Gunst RF, Hess JJ (2003) Statistical Design and Analysis of Experiments-with Applications to Engineering and Science. John Wiley and Sons Inc, Hoboken, New Jersey, USA.

7. Rio DD, Stewart AJ, Mullen W, Burns J, Lean MEJ, et al. (2004) HPLC-MSn analysis of phenolic compounds and purine alkaloids in green and black tea. $J$ Agric and Food Chemistry 52: 2807-2815.

8. Friedman M, Kim SY, Lee SJ, Han GP, Han JS, et al. (2005) Distribution of catechins, theaflavins, caffeine, and theobromine in 77 teas consumed in the United States. Journal of Food Chemistry and Toxicology 70: 550-559.

9. Agilent (2012) Extract from Green Tea. The Essential Chromatography and Spectroscopy Catalog 2011-2012 edition.

10. Stone H, Sidel JL (1993) Sensory Evaluation Practices. Academic Press, Inc, SanDiego.

11. Xu N, Chen Z (2002) Green tea, black tea and semi-fermented tea. In: Tea: Bioactivity and Therapeutic Potential, Boca Raton, FL, USA.

12. Gulati A, Rawat R, Singh B, Ravindranath SD (2003) Application of microwave energy in the manufacture of enhanced-quality green tea. Journal of Agric and Food Chem 51: 4764-4768.

13. Somkiat P, Paveena P, Somchart S (2004) Effective Diffusivity and Kinetics of Urease Inactivation And Color Change During Processing Of Soybeans With Superheated-Steam Fluidized Bed. Drying Technology 22: 2095-2118.

14. Wismer WV, Goonewardene LA (2004) Selection of an astringency reference standard for the evaluation of black tea. Journal of Sensory Studies 19: 119-132.

15. Processing of Sencha Green tea (2012) The crude tea manufacturing process for sencha. 